\title{
$\bullet$ \\ The Detection Techniques for Diagnosis of Renal Cell Carcinoma
}

\author{
IJCRR \\ Section: Healthcare \\ ISI Impact Factor \\ (2019-20): 1.628 \\ IC Value (2019): 90.81 \\ $\operatorname{SJIF}(2020)=7.893$

\section{Yashaswini C1, Shilpa Sivashankar2*, Ashalatha ${ }^{3}$}

'Department of Biotechnology, Acharya Institute of Technology, Karnataka, India; ${ }^{2}$ Department of Biotechnology, Acharya lnstitute of Technol-

ogy, Karnataka, India; ${ }^{3}$ Department of Biotechnology, Acharya Institute of Technology, Karnataka, India.

\section{ABSTRACT}

Introduction: Renal Cell Carcinoma abbreviated as (RCC) occurs inside the kidney tubular coating in the region inside the renal cortex. RCC is one of the riskiest and most aggressive forms of the tumour as its detection, treatment; rate of recurrence is cumbersome and sophisticated. Many detection techniques are available for kidney cell cancer Diagnosis and Staging Carcinoma.

Aims: In this review paper, all such available techniques like Magnetic resonance imaging (MRI), Computerized tomography (CT) and others are discussed and the methods followed in each one of them.

Methodology: The findings of these are analysed for the prognosis, staging and further treatment of RCC.

Results and Conclusion: The new novel methods enclosing the usage of biomarkers present as tumour markers along with body samples are also enclosed which would be more rapid, specific and constitute novel point-of-care biosensors and are also cost-effective.

Key Words: Renal Cell Carcinoma, RCC Detection techniques, Kidney Staging, Biomarkers, Point-of-care device, Biosensors Key Messages: The detection of Renal Cell Carcinoma plays a very important role as there are hurdles for the proper diagnosis and to give on-time treatment or care without allowing the case to be fatal. This review paper discusses all the available techniques for the RCC detection, its pros, corns, expense and also about the recent techniques used for the early diagnosis

\section{INTRODUCTION}

Kidneys are vital organs that perform the function of excretion of waste matter which is otherwise toxic to the normal functioning of cells in the body. The filtering of blood by these organs helps our body to excrete the toxic matter out of the system. Kidneys are very vulnerable and about 850 million adults are affected and impacted by kidney diseases in many regions all over the world, as per the renal experts. ${ }^{1}$ It usually takes the form of CKD (Chronic Kidney Disease) and its presence amongst the world's population at large is 14 per cent.

Another dangerous kidney ailment that causes millions of deaths is Kidney Cell Carcinoma. It is a kind of tumour that arises in the renal tissues in kidney tubules and renal cortex. About four to five per cent of newly discovered tumours are malignant kidney tumours in adults. ${ }^{2}$

\section{Renal Carcinoma:}

Renal cell carcinoma (RCC) is considered one of the world's ten most frequent forms of cancer cases. The heterogeneity related to RCC has been increasing and is very high. Most of it arises either from the kidney tissue epithelium cells or renal cortex cells. For every 1000 people, the number of people who are diagnosed with RCC is about 25 which are quite high. Most of these people have RCC which belongs to the subtypes like clear cell Renal Cell Carcinoma (ccRCC), chromophobe RCC (cRCC) and papillary RCC (pRCC) which is greater than 5\%. Other subtypes of RCC occur in very rare circumstances and are included under the category of unclassified RCC (uRCC). The ccRCC presently is responsible for an $80-85 \%$ mortality rate and is highly dominant in the American race. In the case of benign clear cell tumours, methods like radical and partial nephrectomy (the process of removal of the kidney); ablation (treatment involving intensive heat or cold shocks) and active surveillance (continuous radiography studies) could be made use

\section{Corresponding Author:}

Dr. Shilpa Sivashankar, Department of Biotechnology, Acharya Institute of Technology, Karnataka, India. Email: sshilpa@acharya.ac.in

ISSN: 2231-2196 (Print)

Received: 01.09 .2020
ISSN: 0975-5241 (Online)

Revised: 09.11.2020
Accepted: 28.12 .2020
Published: 22.06.2021 
for the prognosis, diagnosis and its treatment. ${ }^{3}$ The type of tumour named Wilms ' tumour occurs in Children. ${ }^{4}$

\section{Epidemiology:}

All over the globe, the maximum occurrence of renal carcinoma is usually found to occur at the mean age of $60 \pm 15$ years. ${ }^{5}$ It is usually found that the incidence of kidney carcinoma in males is double the rate of that of females and on average, it is at the rate of $2 / 100,000$ and $1 / 100,000$ respectively. The highest aspect ratio of its incidence can be witnessed in the regions of the USA, the Czech Republic and Canada amongst all the developed countries. Asian residents who stay in the USA have a very low incidental rate of renal carcinoma. ${ }^{6}$ The region of Croatia (24.2) has the lowest rate of renal pelvis tumours in comparison to other European regions like Serbia (65.6). The age-standardized rate per 100,000 in Croatia is 24.2, while in Serbia it is around 65.6. The effect due to Balkan nephropathy on renal pelvis tumour is theoretically highly negligible ( Fig 1). Among the USA population, the incidental rate of renal carcinoma differs amongst the race, origin and ethnicity of people all around the world. It is a vital aspect to note that rates are lowest among Pacific Islanders and incident rates in the white Hispanic race are higher in comparison to the Latin American race. ${ }^{7}$

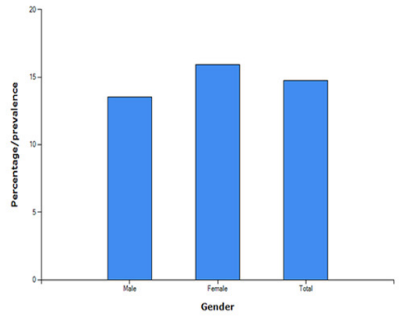

(a)

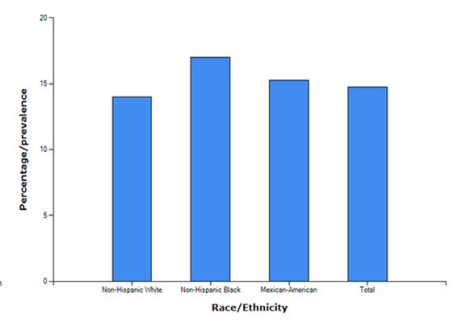

(b)

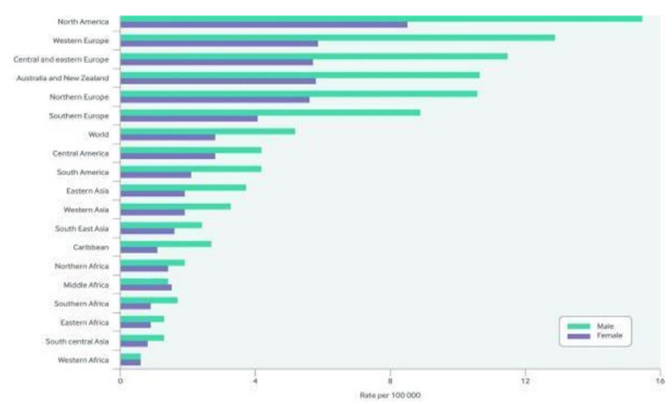

(c)

Figure 1: a) Epidemiology of RCC based on gender b) Epidemiology of RCC based on race c) Epidemiology of RCC based on nationality. ${ }^{89}$

\section{Risk Factors and Causes:}

The common notable risk factors that pose a serious threat to the incidence of kidney carcinoma are:
- Smoking- Tobacco increases the rate of occurrence of renal carcinoma two times. About $30 \%$ and $25 \%$ of kidney tumours in both men, as well as women, are due to smoking respectively.

- Gender - The occurrence rate is two to three times higher in males as compared to females.

- Race- American and African race has a high incidental rate of kidney carcinoma which is $10 \%$ more than the other races in the world.

- Age- The high occurrence of kidney cancer is found between the age group of 50 to 70 years.

- Nutrition and Weight- Obese and malnutrition increase the occurrence of renal carcinoma.

- High blood pressure- Hypertensive patients with Blood pressure (BP) above 140/90 are more prone to RCC.

- Overuse of Medication- Phenacetin containing medications that are banned in parts of the US and are believed to be one of the causes. Diuretics, analgesic painkillers, ibuprofen are also believed to be associated with renal cancer according to studies by Dutcher et al. ${ }^{9}$

- Long-term dialysis- A person who has been on the medical procedure of dialysis for quite a long period more than 5 years are prone to develop cancerous tumour or cysts which may spread.

- Family history related to kidney cancer. ${ }^{10}$

\section{Genetic Alterations in Renal Carcinoma:}

The deletion of the shorter arm of chromosome 3(loss of $3 p)$ constitutes the most frequent genetic alteration linked to the origin of ccRCC. This can be witnessed in about $95 \%$ of the ccRCC cases. The most usual genes associated with ccRCC's pathogenesis are - VHL, PBRM-1, SETD2, BAP1. Other genetic mutations include a slight loss of 14q, 8p deletion, etc. Amongst all the genes Von-Hippel-Lindau gene (VHL) is a suppressor of a tumour kind of gene. Its mechanism and its pathway of action do play a major aspect in the occurrence of ccRCC ( Fig 2). According to the studies done by Nabi et al. The gene called VHL is responsible for coding a protein named $\mathrm{pVHL}$. The formed complex has a major part in the process of breakdown and degradation of proteosome and several intracellular proteins. These intracellular proteins usually bind to the DNA transcripts and create an mRNA to initiate vascular endothelial growth factor abbreviated as (VEGF), which induces the synthesis of high vascular tumors. ${ }^{11}$

\section{DIAGNOSIS}

The 6th and 9th most commonly incidental type of cancer in both men and women is depicted by renal carcinoma amongst all cancers known to date in the world. ${ }^{12}$ It is highly cumbersome to detect renal carcinoma. This is because of the deep position of the reins in the human body..$^{13}$ In the last 15 years, incidental identification of renal tumours has 
increased by $12 \%$ and has become more frequent throughout various diagnostic studies. ${ }^{14}$ Even though ancillary kidney cell carcinomas do possess lower malignancy capacity and low metastasis frequency some cases of small renal carcinomas with related metastasis have been reported. ${ }^{15}$ Incidence differences in the early first era could be clarified by a simple diagnosis and because of the diffusion and regular use of Diagnostic tools such as Ultrasound Scanning, and not due to a real increase in RCC incidence. It is indeed important to notice that, interestingly, that RCC is identified in $1.5 \%$ of autopsies. ${ }^{16}$

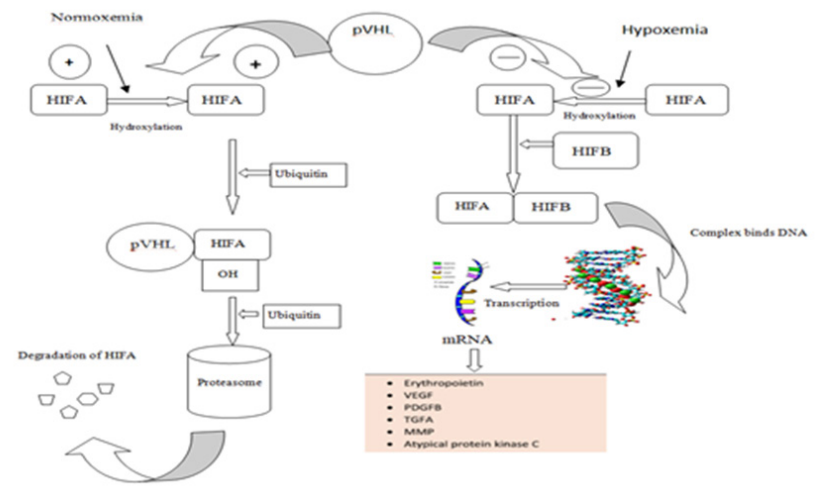

Figure 2: Depicting the pathway of the tumour suppressant VHL gene in tumour suppression ${ }^{11}$

Prognostic methods available to clearly define and provide an explanation about a neural mass include the aforementioned Diagnostic or radiographic assessment studies as follows.

\section{Blood Tests:}

Laboratory tests cannot show for certain whether an individual is suffering from renal carcinoma, but sometimes they can provide the first indication that some kind of kidney problem can occur. They may also help to show if an individual is stable to undergo surgery. ${ }^{17}$ Scientists have found that a Blood marker could aid to analyse and study a person's degree of risk of acquiring renal cancer. It is found that measuring the levels of a protein molecule called KIM-1 in the blood, could suggest whether an individual would be more prone to suffer from RCC for the next decade. ${ }^{18}$ It cannot be confirmed by any blood tests that the RCC is for the definite presence in an individual. But instead, a test called complete blood count (CBC) along with a blood chemistry check will display signs related to kidney cancer by blood studies.

\section{Complete Blood Count (CBC):}

The test measures the overall total number and percentage of possible blood cells. The RCC patients usually exhibit symptoms related to anaemia, while in some cases there are chances of more number of various blood cells displayed due to the condition called polycythaemia. This condition occurs because the renal carcinoma cells release a higher amount of hormone known as erythropoietin. The normal threshold level of erythropoietin in the human body can vary from 3.7 to 36 international units per litre (IU/L). But, in the case of RCC, the levels of erythropoietin rise above 45 international units per litre (IU/L). The respective cost of CBC for cancer detection can range widely from $\$ 50$ to $\$ 670$ based on factors like the type of cancer, parameters and complexity.

\section{Blood chemistry tests:}

Such tests are performed in patients who may have renal carcinoma, as cancer may influence the levels on an average of certain chemicals such as liver enzymes present in the blood, which indicates that cancer might reach or has already reached liver and high optimum levels of calcium ions in the blood indicates that cancer could probably have reached bones. ${ }^{19} 20$ The average cost of this test varies from $\$ 30$ to $\$ 250$.

\section{IMAGINING TECHNIQUES}

\section{CT Scanning}

The computed tomography $(\mathrm{CT})$ has a very prominent role in the initial diagnosis and prognosis of renal carcinoma..$^{21-23}$ The procedure of specialized renal CT test comprises a narrow-section of about 2.5-5 mm helical visualization angle of the kidneys before the intravenous assay agent administration, followed by visualization for about $60-70$ seconds and three to five minutes once the scanning factor assay reagent is studied carefully. ${ }^{24}$ Previously, enhancement for detection was deemed to be present if the lesion attenuation from baseline was enhanced greater than the level of $10 \mathrm{HU} .{ }^{25}$ RCCs can appear as is attenuating, hypoattenuating or hyperattenuating. ${ }^{26}{ }^{27}$ According to the Bosnian categorization of kidney masses there are four classes: Class I encompasses basic cysts and fibroid masses; Class II includes minimally complex yet predominantly benign, harmless masses with narrow septa, hyper attenuation, and slight septal calcification; Class III comprises of mildly complex masses, dense septa, or uneven or dense benign cysts that often require operational exploration; and Class IV includes noticeably complex and usually malignant masses along with dense and uneven regions of enhancement and distinct solids. ${ }^{28}$ Nearly all renal tumours with detectable fat areas are angiomyolipomas (AMLs); however, some AMLs will not include excess fat and many times are confused for RCCs. Increased attenuation on no enhanced $\mathrm{CT}$ testing scans and the aspect ratio related change was beneficial but less important. ${ }^{29} \mathrm{~A}$ falsenegative interpretation may arise if the transient response is not properly assessed pre and post administration of diagnostic content ${ }^{30}$, to check whether the tumour volumes are 
not thoroughly investigated for septa and nodularity, or if in case the tumour amplification is omitted (due to drawbacks leading to constrained levels of improvement at the period of scanning), or when the lesions are too low for appropriate characterization at a period of diagnosis. ${ }^{31}{ }^{32} \mathrm{RCC}$ (particularly the papillary form) is enhanced once the imaging is done quickly post the contrast bolus (throughout the arterial stage) exits. ${ }^{33-36}$ The CT scanning for the complete urinary tract analysis and kidney to detect RCC is approximately $\$ 2800$ (Fig 3). ${ }^{37}$

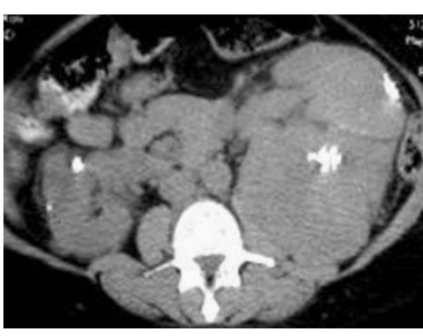

(a)

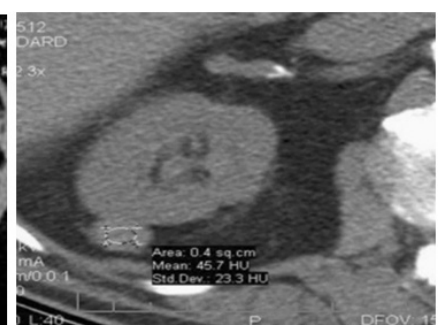

(b)
Figure 3: Renal Carcinoma detected by enhanced type of CT scan for the right kidney. 3839

\section{Magnetic Resonance Imaging:}

MRI reports are identical to $\mathrm{CT}$ results, including masses varying from primary cysts with septa and nodularity to enhanced solids. ${ }^{40}$ The MRI utilizes radio signals, massive magnets and a device to create accurate body images. The MRI will indicate whether the tumour or cancer has spread to the spine and brain. To undertake and perform the procedure, the person is asked to sleep slowly and lie down on a table during the test as it passes into a tube for the scanning process. ${ }^{41}$ If a patient cannot tolerate small confined spaces and is claustrophobic, ${ }^{42}$ then a sedative may be offered before this examination. It takes about 2 to approximately 15 minutes for the scanner to produce an image. There could be a necessity for more than a single set of pictures. On T2-weighted images. ${ }^{43}$ RCCs are usually highly intense. MRI can be particularly useful in examining the upper or lower side views of kidneys, in either coronal or sagittal visualization, and in assessing venous invasion. The degree of precision of MRI treatment is close to that of CT. ${ }^{44}$ This is because, with CT, RCC's false-positive results may occur with many other solid-enhancing lesions (metastatic cancer, lymphoma, oncocytoma, non-fat-containing AML, etc.) that are practically indistinguishable from true masses of renal cell carcinoma when preferably they are discrete and the related background is missing (Fig 4). ${ }^{45}$ The cost for MRI scanning is skyrocketing every day and in present days it costs between $\$ 2600$ to $\$ 10,000 .^{46}$

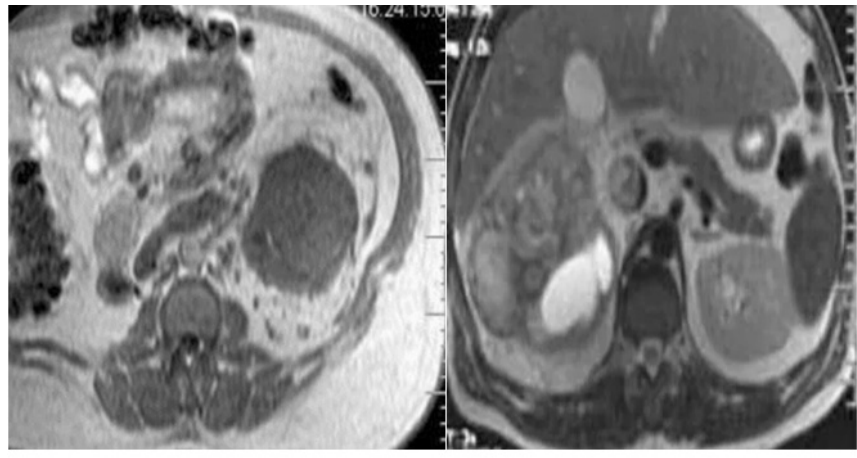

(a)

(b)

Figure 4: Renal Carcinoma Masses detected by MRI scan: (a) Left kidney (b) Right kidney ${ }^{47}$

\section{Ultrasonography (Ultrasound):}

Renal cell cancer on sonogram may be either hyperechoic or isoechoic relative to the rest of the tissue parts within the renal parenchyma. Smaller tumours with much less necrosis appear to always be hyperechoic and could be overanalyzed and mistaken for AMLs. ${ }^{48}$ Isoechoic lesions are identified only by renal contour distortion, focal enhancement of a part of the tissues in the kidney, or central sinus fat distortion. Studies indicate a requirement for comparison-enhanced Doppler US (CEUS) in mass workup showing poor arterial process CT enhancement. ${ }^{49}$ A detection rate of 85 per cent was found in lesions greater than a size of $3 \mathrm{~cm}$ in a recorded sequence. ${ }^{50}$ For lesions greater than the size of $2 \mathrm{~cm}$, the rate of detection was less than 60 per cent was seen. Fallacious-positive results are uncommon because the ultrasound is never the primary modality of imaging used before the operation. A significant Bertin column and fetal lobulation can resemble a solid kidney mass and could be solved with just a devoted CT or MRI test. ${ }^{51}$

False-negative results occur if caution is not taken to completely analyse all the aspects and factors of tissue of the kidney since the ultrasound is extremely operator-dependent. ${ }^{52}$ It is significant to note that tumours that are generally found by chance are at the preliminary and early point of malignancy (Fig. 5). ${ }^{53}$ Furthermore, the associative relationship between clinicopathological observations and the complete clinical profile of inevitable RCC has not tried to be elucidated until now. ${ }^{54}$ The average estimated cost of ultrasound scanning for RCC is comparatively less than CT \& MRI scanning and would range between $\$ 398$ and $\$ 568 .{ }^{43}$ 


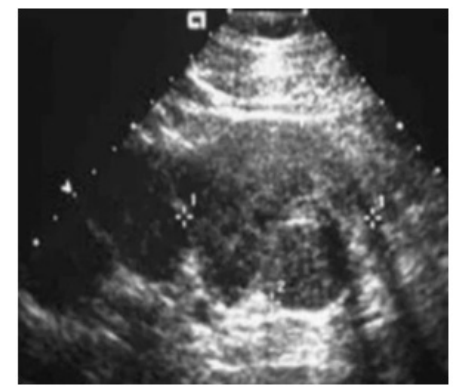

(a)

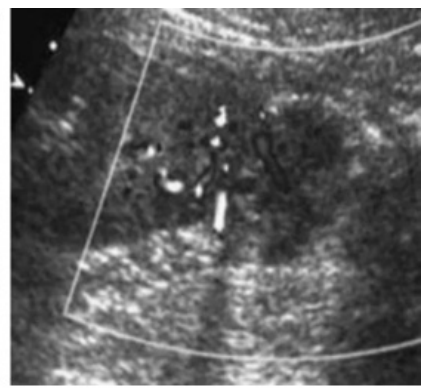

(b)
Figure 5: Renal Carcinoma as imaged in doppler ultrasound: (a) Right kidney (b) Left kidney. ${ }^{55}$

\section{Nuclear Imaging:}

Scintigraphy in nuclear medicine doesn't get used as the main modality in evaluating the alleged RCC. It can also help in distinguishing the assessment of a false mass of tumours. Nuclear medicine experiments in any individual with a potential renal mass aid to distinguish the malignant mass from such a pseudo mass (e.g., Dromedical hump, Bertin board, fetal lobulation). ${ }^{56}$ Scintigraphy using technetium dimethyl succinic acids indicates good absorption in the pseudo mass area, whereas a true mass creates a focused photopenic error. ${ }^{57}$ The precision of the procedure is small because if they are big enough, both forms of masses can induce photopenic defects. ${ }^{58}$ Late-stage illness diagnosis, which tends to occur more frequently as an un-incidentally diagnosed disorder, is not necessarily meant for recovery, and these patients may generally have reduced life periods. ${ }^{59}$ The modelling of the risks ratio also shows that. These results confirm the accurate results of many other researchers who suggest that accidentally detected cancers may be linked to higher survival during diagnosis, mostly because a larger proportion of such natured tumours are studied and diagnosed at an earlier level than cancers that are not incidentally detected. ${ }^{60}$ The cost estimated for nuclear imaging for RCC ranges from $\$ 135$ to $\$ 1138 .{ }^{61}$

\section{Positron Emission Tomography (PET):}

For several cancers, fluorodeoxyglucose -F 18 (FDG) positron emission tomography (PET) has become an accepted imaging process. FDG-PET technology makes prominent use of the improved glycolysis intensity correlated with neoplastic tissues. PET has effectively been proved effective in pulmonary imaging ${ }^{62}$ head and neck ${ }^{63}$ colorectal, ${ }^{64}$ breasts, ${ }^{65}$ and also for other cancers. Wahl et al first investigated the enthusiastic adoption of FDG by kidney tumours in $1991 .{ }^{66}$ Although some research indicates a high accuracy for PET, ${ }^{67}$ ${ }^{68}$ others consider high false negative (FN) levels that bring into question the diagnostic usage of the scan. ${ }^{69-71}$ As a result, the vital function of FDG-PET in the evaluation and treatment of predominant and metastatic kidney cancer (RCC) has still not been thoroughly established. Safaei - et al tested 36 individuals with enhanced RCC and reported that PET was $100 \%$ accurate if used in particular for the clinical-stage classification. ${ }^{72}$ Significantly, PET results were studied found to be 100 per cent responsive to primary lesions, metastasisrelated to the retroperitoneal lymph node/kidney zone recurrences, liver and bony tumour metastasis. ${ }^{73}$ The PET-positive and reliable statistical values of 98.4 per cent and 100.0 per cent for soft tissue for bony tumours suggest the use of PET as a supportive major issue-solving method when traditional scans become sceptical of metastatic Renal carcinoma but contradictory. Although it was not possible to replicate the $100 \%$ sensitivity observed by Wu et al, the $100 \%$ sensitivity that was observed agrees with their findings, wherein zero among 12 benign types of bone tumours showed positive results for PET ( Fig 6) ${ }^{74}$ The estimated cost of PET scan along with CT imaging is more than $\$ 5000 .^{75}$

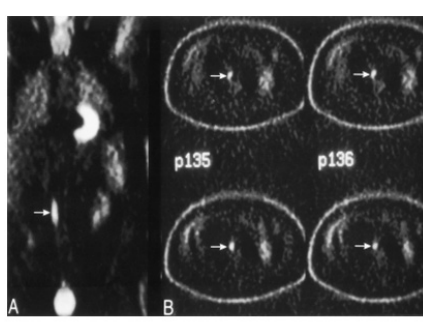

(a)

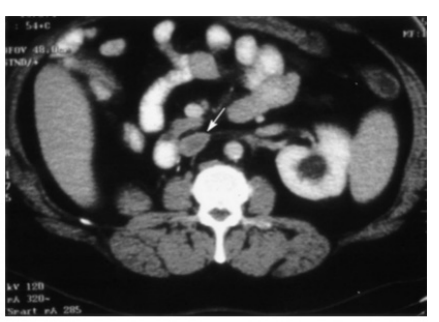

(b)
Figure 6: Kidney Cancer as detected by PET scan: (a) Coronal view (b) Axial view. ${ }^{76}$

\section{Intravenous Pyelogram - (IVP):}

Intravenous pyelogram (IVP) is a sequence of kidney $\mathrm{X}$ rays, ureters, including bladder with a fluorescent dye being pumped into another vena. The photographs are often used for identifying cancers, defects, kidney stones, or other obstructions, and for testing the distribution factor of renal blood. These are also used as a diagnostic tool for certain disorders or to test the spread of bladder related cancer to other urinary tract regions. ${ }^{77} \mathrm{An}$ intravenous pyelogram (IVP) is a liver, ureter, and urinary bladder $\mathrm{x}$-ray test using iodinated comparison content inserted gently into the veins. An x-ray (radiograph) is a type of necessary medical examination that is non-invasive and helps doctors accurately diagnose a patient's medical conditions. The usually utilized equipment for this test comprises a radiographic bench, one or two x-ray tubes, and a TV-like display situated in the examining room. Fluoroscopy, which transforms $\mathrm{x}$-rays to video images, is used widely to track and direct computational development. The video is created by an x-ray system and a detector hanging over a table on which the patient is asked to sit. $^{78}$ The average estimated price range for the test is between $\$ 50$ and $\$ 100$ based on area, cost and availability variables. ${ }^{79}$ 


\section{Angiography:}

Non-invasive cross-sectional visualization (CT, MRI, US) has substituted angiography with known or presumed RCC in the patient workup. Angiography is often used sometimes where the location spot of a tumour is not known (e.g., renal vs. adrenal). In such patients, it might be necessary to inject exclusively the renal as well as adrenal arteries, and external vessels. Renal angiography (also known as arteriography)-a collection of X-rays of the internal renal blood arteries using a contrast dye injected directly into a catheter that is inserted into the blood vessels of the renal to find any symptoms of blockage or anomalies influencing blood flow to the kidneys. ${ }^{80}$

In India, the rate of renal angioplasty begins at around $\$ 3000$. India's renal angioplasty rates are among the lowest and economic in the country. ${ }^{81}$

\section{BIOPSY}

Once a positive diagnostic study of renal mass is made, effective treatment can be implemented without further examination. For example, if a mass displays characteristic aspects of carcinoma, clinical resection, if necessary, may be performed before pre-operative biopsy since the pre-operative risk of disease will be strong enough; a negative biopsy result will not necessarily change management. ${ }^{82}$ Similarly, for certain benign masses, reported imaging guidelines to apply, such as clear cysts ${ }^{83}$ hyperdense cysts, ${ }^{84}$ and fat-consisting angiomyolipomas, ${ }^{8586}$ which can be treated with a strong degree of trust. Accordingly, the renal tumour mass biopsy was traditionally intended for a small range of indications. ${ }^{87}$ The biopsy was as well as found to change clinical treatment in 60.5 per cent of patients receiving a biopsy ${ }^{88}$ When performing a renal mass biopsy, several technical factors that may highly affect the rates of diagnosis and complications have to be taken into account. The method has its pros and cons. ${ }^{89-92}$ Usually small (20-gage or thinner) needle samples are histologically studied on the cytological and wide (19-gage or larger) needle samples. It's difficult to equate the testing efficacy of small and large needles. ${ }^{93}$ Caoili et al. ${ }^{94}$ treated 92 per cent of lesions and Neuzillet et al. ${ }^{95}$ utilizing 18 -gage needles alone. The precise size of the solid renal tumour mass is the key criterion for deciding the functioning capacity of biopsy in this evolving sign. Surgical evidence has repeatedly shown that as the scale of a very strong renal mass declines, the probability that it will reflect a benevolent object increases. ${ }^{96-102}$ Such masses have traditionally undergone needless surgical resection since they really cannot be separated from imaging alone from malignant lesions ( Fig 7) ${ }^{103-107}$ Kidney biopsy expenses vary from $\$ 1,724$ to $\$ 3,158$, respectively. While the national average amounts up to $\$ 4915 .{ }^{108}$

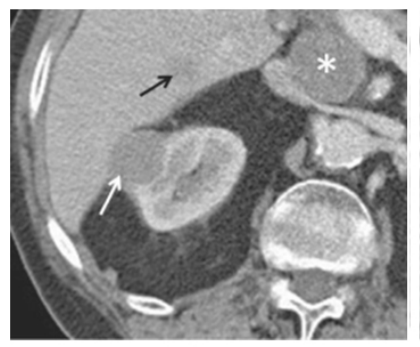

(a)

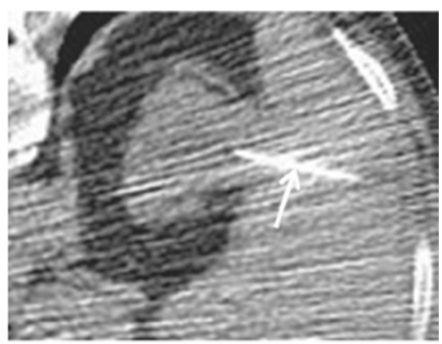

(b)
Figure 7: Image depicting percutaneous biopsy through CT scanning. ${ }^{109}$

\section{Kidney Staging:}

Staging cancer always is the method of assessing the degree and duration of the early primary tumour's distribution. Staging cancer promotes the exchanging of knowledge between physicians and experts inside and through organizations offering a framework for evaluating cases through areas, ages, and modalities of care ( Table 1). The American Joint Committee on Cancer (AJCC) staging of tumour-node-metastasis (TNM) is the most commonly established and universally accepted form of cancer staging. ${ }^{110}$ AJCC key staging of tumours for RCC in various contrast of staging with the suggested changes by Shao et al. ${ }^{11}$

\section{Table 1: Summary of AJCC key staging of tumours for RCC ${ }^{\text {II }}$}

\begin{tabular}{ll} 
Tumour Stage & Assessment \\
TX & Testing of primary tumour cannot be done \\
To & Primary tumour's evidence is not found \\
T1 $($ Stage 1$)$ & Tumour size is $\leq 7 \mathrm{~cm}$ and within the kidney \\
$\mathrm{T}_{2}$ (Stage 2) & Tumour size is $>7 \mathrm{~cm}$ and within the kidney \\
$\mathrm{T}_{3}$ (Stage 3$)$ & $\begin{array}{l}\text { Tumour spread into major veins and some- } \\
\text { times, adrenal gland }\end{array}$ \\
$\mathrm{T}_{4}$ (Stage 4) & $\begin{array}{l}\text { Tumour invades outside Gerota's fascia and } \\
\text { metastasis }\end{array}$ \\
\hline
\end{tabular}

All the above-mentioned techniques of detection are very expensive and are not affordable by all people worldwide due to economic constraints. These methods are also time taking, not so specific and painful. Hence, novel approaches are being developed at a faster pace for the rapid, painless, more specific and low-cost diagnosis, which serves as a platform for the early detection and diagnosis of RCC.

\section{RECENT, NOVEL DETECTION TECHNIQUE}

Detection through Biomarkers cancer-related biomarker means and refers specifically to a molecule that is released by 
the tumour cells and the predominant presence of this protein in any body's biological fluids suggests a probable occurrence of cancer. The best-known cancer biomarkers that have been abruptly used recently to detect early disease of Renal Carcinoma are Aquaporin, Perilipin and ADFP (Adipose differentiation-related protein) in the urine sample. ${ }^{112}$ The researchers compared the elevated levels of these tumour biomarkers in the patients to the healthy controls, where there was very little concentration of the proteins. ${ }^{113}$ The results suggest that the patients with RCC contained a higher concentration of Aquaporin-1 (Spearman coefficient $\mathrm{P}=0.78$ ) than the healthy controls (Spearman coefficient $\mathrm{P}<0.001$ ). Similarly, the Perilipin-2 levels in the patients with RCC (Spearman coefficient $\mathrm{P}=0.30$ ) were in higher concentrations than the healthy controls (Spearman coefficient $\mathrm{P}<0.001$ ). The final results also suggest that the Pre-nephrectomy AQP1 and PLIN2 concentrations were positively correlated with tumour size. These proteins are retrieved from body samples like urine and are tested by designing specific biosensors. Though there are many biomarkers for the diagnosis of renal diseases, only Aquaporin-1 and Perilipin -2 are specific to renal cell carcinoma. The analysis can be performed by using various substrates like paper, biomembranes, by using nanotechnology, ${ }^{114}$ etc. This constitutes the production of a more reliable and specific detection platform that serves as a rapid, cost-effective and point-of-care novel diagnostic tool. In the future, we would like to fabricate and develop a simple platform-based system, which would allow for the fast detection and diagnosis of Renal Cell Carcinoma (RCC) at the very preliminary stages of carcinoma. This would not only reduce the risk of the advancement of the RCC to critical stages but also acts as a successful preventive measure to cure it at much earlier stages. It also almost completely avoids the high fees for the promising treatment of RCC which would include surgical methods of removal of the tumour, kidney transplant or chemotherapy.

\section{CONCLUSION}

Renal Cell Carcinoma has risen in its position of incidence in the last decade and its detection is not simple due to many reasons for the cost, complexity and dense packing fashion of nephrons in kidneys. Hence, the most widely and commonly used techniques used for the study and diagnosis and detection of RCC include studying blood chemistry, urine sample studies and other imaging techniques which include MRI, CT, Ultrasound, etc. These methods though are the most well-known and common ones that are presently used; there is a need to find methods for a more specific and reliable diagnosis.

Hence, recent developments and advances in the discovery of tumour-related biomarkers and designing techniques of biosensors to detect the cancer biomarkers specific to RCC are found which will serve as a point-of-care and novel platform. We are also aiming to create and design a system for early and rapid detection of RCC which would also be a costeffective platform.

\section{ACKNOWLEDGMENT}

Authors acknowledge the immense help received from the scholars whose articles are cited and included in references of this manuscript. Authors are also grateful to authors / editors / publishers of all those articles, journals and books from where the literature of this article has been reviewed and discussed.

\section{Conflict of Interest: NIL}

\section{Source of Funding: NIL}

\section{REFERENCES}

1. Lights V. Kidney Cancer [Internet]. Healthline.com. 2012 [cited 2020 Nov 24]. Available from: https:/www.healthline.com/ health/kidney-cancer

2. Hu R, Gupta R, Wang Z, Wang C, Sun H, Singamaneni S, et al. Bioplasmonic paper-based assay for perilipin-2 non-invasively detects renal cancer. Kidney Int. 2019;96(6):1417-21.

3. Hsieh JJ, Purdue MP, Signoretti S, Swanton C, Albiges L, Schmidinger M, et al. Renal cell carcinoma. Nat Rev Dis Primers. 2017;3:17009.

4. Coppin C, Porzsolt F. Kidney Cancer. In: Evidence-based Oncology. London, UK: BMJ Publishing Group; 2007. p. 333-45.

5. Agnihotri S, Kumar J, Jain M, Kapoor R, Mandhani A. Renal cell carcinoma in India demonstrates early age of onset \& a late stage of presentation. Indian J Med Res. 2014;140(5):624-9.

6. Abraham GP, Cherian T, Mahadevan P, Avinash TS, George D, Manuel E. Detailed study of survival of patients with renal cell carcinoma in India. Indian J Cancer. 2016;53(4):572-4.

7. Chow W-H, Dong LM, Devesa SS. Epidemiology and risk factors for kidney cancer. Nat Rev Urol. 2010;7(5):245-57.

8. Ridge CA, Pua BB, Madoff DC. Epidemiology and staging of renal cell carcinoma. Semin Intervent Radiol. 2014;31(1):3-8.

9. Dutcher JP. Recent developments in the treatment of renal cell carcinoma. Ther Adv Urol. 2013;5(6):338-53.

10. Kidney cancer - risk factors and prevention [Internet]. Cancer. net. 2012 [cited 2020 Nov 24]. Available from: https://www. cancer.net/cancer-types/kidney-cancer/risk-factors-and-prevention

11. Nabi S, Kessler ER, Bernard B, Flaig TW, Lam ET. Renal cell carcinoma: a review of biology and pathophysiology. F1000Res. 2018;7:307.

12. Gaudette LA, Hill GB. Canadian cancer statistics 1990. Health Rep. 1990;2(2):103-26.

13. Yagoda A. Cytotoxic chemotherapy phase II trials between 1983 and 1990 for advanced renal cell carcinoma. In: Basic and Clinical Research on Renal Cell Carcinoma. Berlin, Heidelberg: Springer Berlin Heidelberg; 1992. p. 71-8.

14. Richie JP, Kantoff PW. Renal Cell Carcinoma. Shelton, CT: B.C. Decker; 2003.

15. Amendola MA, Bree RL, Pollack HM, Francis IR, Glazer GM, Jafri SZH, et al. Small renal cell carcinomas: Resolving a diagnostic dilemma. J Urol. 1989;141(1):201-201. 
16. UpToDate [Internet]. Uptodate.com. [cited 2020 Nov 24]. Available from: https://www.uptodate.com/contents/epidemiology-pathology-and-pathogenesis-of-renal-cell-carcinoma

17. Patel N, Cranston D, Sullivan M. The aetiology, epidemiology, clinical features, and investigation of kidney cancer. Catto JWF, editor. Oxford University Press; 2017.

18. Cancer Research UK. Blood test could detect kidney cancer up to 5 years earlier. Science Daily [Internet]. 2018 Aug 13 [cited 2020 Nov 24]; Available from: https://www.sciencedaily.com/ releases/2018/08/180813113456.htm

19. Tests for Kidney Cancer [Internet]. Cancer.org. [cited 2020 Nov 24]. Available from: http://www.cancer.org/cancer/kidney-cancer/detection-diagnosis-staging/how-diagnosed.html

20. Kidney Cancer: Diagnosis [Internet]. Rochester.edu. [cited 2020 Nov 24]. Available from: http://www.urmc.rochester. edu/encyclopedia/content.aspx ?contenttypeid $=34 \&$ content $\mathrm{id}=17768-1$

21. Guzzo TJ, Pierorazio PM, Schaeffer EM, Fishman EK, Allaf ME. The accuracy of multidetector computerized tomography for evaluating tumor thrombus in patients with renal cell carcinoma. J Urol. 2009;181(2):486-90; discussion 491.

22. Bulnes Vázquez V, Alvarez-Múgica M, Fernández Gómez JM, Nava Tomás E, Jalón Monzón A, Meilán Martínez A. Clinicopathologic features of renal cell carcinoma incidentally detected through radiological studies. Actas Urol Esp. 2008;32(10):976-84.

23. Gabr AH, Gdor Y, Roberts WW, Wolf JS Jr. Radiographic surveillance of minimally and moderately complex renal cysts. BJU Int. 2009;103(8):1116-9.

24. Young JR, Margolis D, Sauk S, Pantuck AJ, Sayre J, Raman SS. Clear cell renal cell carcinoma: discrimination from other renal cell carcinoma subtypes and oncocytoma at multiphasic multidetector CT. Radiology. 2013;267(2):444-53.

25. Bae KT, Heiken JP, Siegel CL, Bennett HF. Renal cysts: is attenuation artifactually increased on contrast-enhanced CT images? Radiology. 2000;216(3):792-6.

26. Birnbaum BA, Jacobs JE, Ramchandani P. Multiphasic renal CT: comparison of renal mass enhancement during the corticomedullary and nephrographic phases. Radiology. 1996;200(3):753-8.

27. Coulam CH, Sheafor DH, Leder RA, Paulson EK, DeLong DM, Nelson RC. Evaluation of pseudoenhancement of renal cysts during contrast-enhanced CT. AJR Am J Roentgenol. 2000; 174(2):493-8.

28. Heneghan JP, Spielmann AL, Sheafor DH, Kliewer MA, DeLong DM, Nelson RC. Pseudoenhancement of simple renal cysts: a comparison of single and multidetector helical CT. J Comput Assist Tomogr. 2002;26(1):90-4.

29. Kim JK, Park S-Y, Shon J-H, Cho K-S. Angiomyolipoma with minimal fat: differentiation from renal cell carcinoma at biphasic helical CT. Radiology. 2004;230(3):677-84.

30. Kopka L, Fischer U, Zoeller G, Schmidt C, Ringert RH, Grabbe E. Dual-phase helical CT of the kidney: value of the corticomedullary and nephrographic phase for evaluation of renal lesions and preoperative staging of renal cell carcinoma. AJR Am J Roentgenol. 1997;169(6):1573-8.

31. Lockhart ME, Smith JK. Technical considerations in renal CT. Radiol Clin North Am. 2003;41(5):863-75.

32. Macari M, Bosniak MA. Delayed CT to evaluate renal masses incidentally discovered at contrast-enhanced CT: demonstration of vascularity with deenhancement. Radiology. 1999;213(3):674-80.

33. Maki DD, Birnbaum BA, Chakraborty DP, Jacobs JE, Carvalho BM, Herman GT. Renal cyst pseudoenhancement: beam-hardening effects on CT numbers. Radiology. 1999;213(2):468-72.
34. Scatarige JC, Sheth S, Corl FM, Fishman EK. Patterns of recurrence in renal cell carcinoma: manifestations on helical CT: Manifestations on helical CT. AJR Am J Roentgenol. 2001;177(3):653-8.

35. Siegel CL, Fisher AJ, Bennett HF. Interobserver variability in determining enhancement of renal masses on helical CT. AJR Am J Roentgenol. 1999;172(5):1207-12.

36. Szolar DH, Kammerhuber F, Altziebler S, Tillich M, Breinl E, Fotter R, et al. Multiphasic helical CT of the kidney: increased conspicuity for detection and characterization of small (<3-cm) renal masses. Radiology. 1997;202(1):211-7.

37. Bendbulletin.com. [cited 2020 Nov 24]. Available from: https:// www.bendbulletin.com/lifestyle/health/big-price-differencebetween-ct-scans-and-ultrasounds-at-st/article_f7c7c50b04ad-5376-b4a3-fcf25b029437.html

38. Takebayashi S, Hidai H, Chiba T, Takagi H, Koike S, Matsubara S. Using helical CT to evaluate renal cell carcinoma in patients undergoing hemodialysis: value of early enhanced images. AJR Am J Roentgenol. 1999;172(2):429-33.

39. Zeman RK, Zeiberg A, Hayes WS, Silverman PM, Cooper C, Garra BS. Helical CT of renal masses: the value of delayed scans. AJR Am J Roentgenol. 1996;167(3):771-6.

40. Juluru K, Vogel-Claussen J, Macura KJ, Kamel IR, Steever A, Bluemke DA. MR imaging in patients at risk for developing nephrogenic systemic fibrosis: protocols, practices, and imaging techniques to maximize patient safety. Radiographics. 2009;29(1):9-22.

41. Hill KL, Lipson AC, Sheehan JM. Brain magnetic resonance imaging changes after sorafenib and sunitinib chemotherapy in patients with advanced renal cell and breast carcinoma: Clinical article. J Neurosurg. 2009;111(3):497-503.

42. Jinzaki M, Akita H, Oya M. Imaging features of renal cell carcinoma differential diagnosis, staging, and posttreatment evaluation. In: Renal Cell Carcinoma. Tokyo: Springer Japan; 2017. p. 139-76.

43. Choyke PL. Detection and staging of renal cancer. Magn Reson Imaging Clin N Am. 1997;5(1):29-47.

44. Sun MRM, Ngo L, Genega EM, Atkins MB, Finn ME, Rofsky NM, et al. Renal cell carcinoma: dynamic contrast-enhanced MR imaging for differentiation of tumour subtypes--correlation with pathologic findings. Radiology. 2009;250(3):793-802.

45. Narumi Y, Hricak H, Presti JC Jr, Forstner R, Sica GT, Kuroda $\mathrm{C}$, et al. MR imaging evaluation of renal cell carcinoma. Abdom Imaging. 1997;22(2):216-25.

46. Reed E. How much does an MRI cost? [Internet]. Thestreet. com. 2019 [cited 2020 Nov 24]. Available from: https:// www.thestreet.com/lifestyle/health/how-much-does-an-mricost- 14972340

47. Yoshimitsu K, Honda H, Kuroiwa T, Irie H, Tajima T, Jimi M, et al. MR detection of cytoplasmic fat in clear cell renal cell carcinoma utilizing chemical shift gradient-echo imaging. J Magn Reson Imaging. 1999;9(4):579-85.

48. Tamai H, Takiguchi Y, Oka M, Shingaki N, Enomoto S, Shiraki $\mathrm{T}$, et al. Contrast-enhanced ultrasonography in the diagnosis of solid renal tumours. J Ultrasound Med. 2005;24(12):1635-40.

49. Tamas-Szora A, Socaciu M, Crișan N, Dobrotă F, Prunduș P, Bungărdean $C$, et al. Investigation of renal cell carcinoma by contrast-enhanced ultrasound- predictive value of time-intensity curve analysis in establishing local tumour invasion and stage: A pilot study. Urol J. 2015;12(3):2173-81.

50. Warshauer DM, McCarthy SM, Street L, Bookbinder MJ, Glickman MG, Richter J, et al. Detection of renal masses: Sensitivities and specificities of excretory urography/linear tomography, US, and CT. J Urol. 1989;141(4):1034-1034. 
51. Kier R, Taylor KJ, Feyock AL, Ramos IM. Renal masses: characterization with Doppler US. Radiology. 1990;176(3):703-7.

52. Kuijpers D, Jaspers R. Renal masses: differential diagnosis with pulsed Doppler US. Radiology. 1989;170(1 Pt 1):59-60.

53. Ramos IM, Taylor KJW, Kier R, Burns PN, Snower DP, Carter D. Tumor vascular signals in renal masses: Detection with Doppler US. J Urol. 1989;141(4):1036-1036.

54. Porena M, Vespasiani G, Rosi P, Costantini E, Virgili G, Mearini E, et al. Incidentally detected renal cell carcinoma: role of ultrasonography. J Clin Ultrasound. 1992;20(6):395-400.

55. Vallancien G, Torres LO, Gurfinkel E, Veillon B, Brisset JM. Incidental detection of renal tumours by abdominal ultrasonography. Eur Urol. 1990;18(2):94-6.

56. Ueda T, Mihara Y. Incidental detection of renal carcinoma during radiological imaging. Br J Urol. 1987;59(6):513-5.

57. Thompson IM, Peek M. Improvement in the survival of patients with renal cell carcinoma--the role of the serendipitously detected tumour. J Urol. 1988;140(3):487-90.

58. Jubelirer SJ, Rubin M. The use of modern radiologic methods in identifying incidental renal cell carcinoma. W V Med J. 1993;89(1):21-3.

59. Bretheau D, Lechevallier E, Eghazarian C, Grisoni V, Coulange C. Prognostic significance of incidental renal cell carcinoma. Eur Urol. 1995;27(4):319-23.

60. Lightfoot N, Conlon M, Kreiger N, Bissett R, Desai M, Warde $\mathrm{P}$, et al. Impact of noninvasive imaging on increased incidental detection of renal cell carcinoma. Eur Urol. 2000;37(5):521-7.

61. Sistrom CL, McKay NL. Costs, charges, and revenues for hospital diagnostic imaging procedures: differences by modality and hospital characteristics. J Am Coll Radiol. 2005;2(6):5119.

62. Scott WJ, Schwabe JL, Gupta NC, Dewan NA, Reeb SD, Sugimoto JT. Positron emission tomography of lung tumours and mediastinal lymph nodes using [18F]fluorodeoxyglucose. Ann Thorac Surg. 1994;58(3):698-703.

63. Bailet JW, Abemayor E, Jabour BA, Hawkins RA, Ho C, Ward PH. Positron emission tomography: a new, precise imaging modality for detection of primary head and neck tumours and assessment of cervical adenopathy: A new, precise imaging modality for detection of primary head and neck tumours and assessment of cervical adenopathy. Laryngoscope. 1992;102(3):281-8.

64. Schiepers C, Penninckx F, De Vadder N, Merckx E, Mortelmans L, Bormans G, et al. Contribution of PET in the diagnosis of recurrent colorectal cancer: comparison with conventional imaging. Eur J Surg Oncol. 1995;21(5):517-22.

65. Avril N, Dose J, Jänicke F, Ziegler S, Römer W, Weber W, et al. Assessment of axillary lymph node involvement in breast cancer patients with positron emission tomography using radiolabeled 2-(fluorine-18)-fluoro-2-deoxy-D-glucose. J Natl Cancer Inst. 1996;88(17):1204-9.

66. Wahl RL, Harney J, Hutchins G, Grossman HB. Imaging of renal cancer using positron emission tomography with 2-deoxy2-(18F)-fluoro-D-glucose: pilot animal and human studies. J Urol. 1991;146(6):1470-4.

67. Ramdave S, Thomas GW, Berlangieri SU, Bolton DM, Davis I, Danguy HT, et al. Clinical role of F-18 fluorodeoxyglucose positron emission tomography for detection and management of renal cell carcinoma. J Urol. 2001;166(3):825-30.

68. Goldberg MA, Mayo-Smith WW, Papanicolaou N, Fischman AJ, Lee MJ. FDG PET characterization of renal masses: preliminary experience. Clin Radiol. 1997;52(7):510-5.

69. Bachor R, Kotzerke J, Gottfried HW, Brändle E, Reske SN, Hautmann R. Positron emission tomography in diagnosis of renal cell carcinoma. Urologe A. 1996;35(2):146-50.
70. Miyauchi T, Brown RS, and Grossman HB. Correlation between the visualization of primary renal cancer by FDG-PET and histopathological findings. In: Forty-third Annual Meeting of the Society of Nuclear Medicine. Denver, Colorado; 1996.

71. Miyakita H, Tokunaga M, Onda H, Usui Y, Kinoshita H, Kawamura N, et al. Significance of $18 \mathrm{~F}$-fluorodeoxyglucose positron emission tomography (FDG-PET) for detection of renal cell carcinoma and immunohistochemical glucose transporter 1 (GLUT-1) expression in cancer. Int J Urol. 2002;9(1):15-8.

72. Safaei A, Figlin R, Hoh CK, Silverman DH, Seltzer M, Phelps $\mathrm{ME}$, et al. The usefulness of F-18 deoxyglucose whole-body positron emission tomography (PET) for re-staging of renal cell cancer. Clin Nephrol. 2002;57(1):56-62.

73. Kang DE, White RL Jr, Zuger JH, Sasser HC, Teigland CM. Clinical use of fluorodeoxyglucose $\mathrm{F} 18$ positron emission tomography for detection of renal cell carcinoma. J Urol. 2004;171(5):1806-9.

74. Wu HC, Yen RF, Shen YY, Kao CH, Lin CC, Lee CC. Comparing whole body $18 \mathrm{~F}-2$-deoxyglucose positron emission tomography and technetium-99m methylene diphosphate bone scan to detect bone metastases in patients with renal cell carcinomas - a preliminary report. J Cancer Res Clin Oncol. 2002;128(9):503-6.

75. ABIM Foundation. PET scans after cancer treatment [Internet]. Choosingwisely.org. [cited 2020 Nov 24]. Available from: https://www.choosingwisely.org/patient-resources/pet-scansafter-cancer-treatment/

76. Chiarello MA, Mali RD, Kang SK. Diagnostic accuracy of MRI for detection of papillary renal cell carcinoma: A systematic review and meta-analysis. AJR Am J Roentgenol. 2018;211(4):812-21.

77. Intravenous pyelogram [Internet]. Stanfordhealthcare.org. [cited 2020 Nov 24]. Available from: https://stanfordhealthcare. org/medical-conditions/cancer/kidney-cancer/kidney-cancerdiagnosis/intravenous-pyelogram.html

78. Radiological Society of North America (RSNA), American College of Radiology (ACR). IVP - Intravenous Pyelogram [Internet]. Radiologyinfo.org. [cited 2020 Nov 24]. Available from: https://www.radiologyinfo.org/en/info.cfm?pg=ivp

79. X-Ray IVP Test [Internet]. Lybrate.com. [cited 2020 Nov 24]. Available from: https://www.lybrate.com/lab-test/x-ray-ivp

80. Stanford Health Care [Internet]. Stanfordhealthcare.org. [cited 2020 Nov 24]. Available from: https://stanfordhealthcare.org/ medical-conditions/cancer/kidney-cancer/kidney-cancer-diagnosis/renal-angiography.html

81. Lyfboat. Renal Angioplasty Cost in India [Internet]. Lyfboat. com. Lyfboat; [cited 2020 Nov 24]. Available from: https:// www.lyfboat.com/renal-angioplasty-cost-hospitals-surgeonsin-india/

82. Curry NS, Reinig J, Schabel SI, Ross P, Vujic I, Gobien RP. An evaluation of the effectiveness of CT vs. other imaging modalities in the diagnosis of atypical renal masses. Invest Radiol. 1984;19(5):447-54.

83. Bosniak MA. The current radiological approach to renal cysts. Radiology. 1986;158(1):1-10.

84. Bosniak MA. The small (less than or equal to $3.0 \mathrm{~cm}$ ) renal parenchymal tumor: detection, diagnosis, and controversies. Radiology. 1991;179(2):307-17.

85. Bosniak MA, Megibow AJ, Hulnick DH, Horii S, Raghavendra BN. CT diagnosis of renal angiomyolipoma: The importance of detecting small amounts of fat. J Urol. 1989;141(4):10361036.

86. Bosniak MA. Angiomyolipoma (hamartoma) of the kidney: a preoperative diagnosis is possible in virtually every case. Urol Radiol. 1981;3(3):135-42. 
87. Silverman SG, Gan YU, Mortele KJ, Tuncali K, Cibas ES. Renal masses in the adult patient: the role of percutaneous biopsy. Radiology. 2006;240(1):6-22.

88. Maturen KE, Nghiem HV, Caoili EM, Higgins EG, Wolf JS Jr, Wood DP Jr. Renal mass core biopsy: accuracy and impact on clinical management. AJR Am J Roentgenol. 2007;188(2):56370.

89. Lechevallier E, André M, Barriol D, Daniel L, Eghazarian C, De Fromont M, et al. Fine-needle percutaneous biopsy of renal masses with helical CT guidance. Radiology. 2000;216(2):50610.

90. Johnson PT, Nazarian LN, Feld RI, Needleman L, Lev-Toaff AS, Segal SR, et al. Sonographically guided renal mass biopsy: indications and efficacy. J Ultrasound Med. 2001;20(7):74953; quiz 755.

91. Tang S, Li JHC, Lui SL, Chan TM, Cheng IKP, Lai KN. Freehand, ultrasound-guided percutaneous renal biopsy: experience from a single operator. Eur J Radiol. 2002;41(1):65-9.

92. Silverman SG, Collick BD, Figueira MR, Khorasani R, Adams DF, Newman RW, et al. Interactive MR-guided biopsy in an open-configuration MR imaging system. Radiology. 1995;197(1):175-81.

93. Richter F, Kasabian NG, Irwin RJ Jr, Watson RA, Lang EK. Accuracy of diagnosis by guided biopsy of renal mass lesions classified indeterminate by imaging studies. Urology. 2000;55(3):348-52.

94. Caoili EM, Bude RO, Higgins EJ, Hoff DL, Nghiem HV. Evaluation of sonographically guided percutaneous core biopsy of renal masses. AJR Am J Roentgenol. 2002;179(2):373-8.

95. Neuzillet Y, Lechevallier E, Andre M, Daniel L, Coulange C. Accuracy and clinical role of fine-needle percutaneous biopsy with computerized tomography guidance of small (less than 4.0 $\mathrm{cm}$ ) renal masses. J Urol. 2004;171(5):1802-5.

96. Ozen H, Colowick A, Freiha FS. Incidentally discovered solid renal masses: what are they? Br J Urol. 1993;72(3):274-6.

97. Beland MD, Mayo-Smith WW, Dupuy DE, Cronan JJ, DeLellis RA. Diagnostic yield of 58 consecutive imaging-guided biopsies of solid renal masses: should we biopsy all that is indeterminate? AJR Am J Roentgenol. 2007;188(3):792-7.

98. Duchene DA, Lotan Y, Cadeddu JA, Sagalowsky AI, Koeneman KS. Histopathology of surgically managed renal tumours: analysis of a contemporary series. Urology. 2003;62(5):82730.

99. Li G, Cuilleron M, Gentil-Perret A, Tostain J. Characteristics of image-detected solid renal masses: implication for optimal treatment. Int J Urol. 2004;11(2):63-7.

100. Frank I, Blute ML, Cheville JC, Lohse CM, Weaver AL, Zincke H. Solid renal tumours: an analysis of pathological features related to tumour size. J Urol. 2003;170(6 Pt 1):2217-20.
101. McKiernan J, Yossepowitch O, Kattan MW, Simmons R, Motzer RJ, Reuter VE, et al. Partial nephrectomy for renal cortical tumours: pathologic findings and impact on the outcome. Urology. 2002;60(6):1003-9.

102. Silver DA, Morash C, Brenner P, Campbell S, Russo P. Pathologic findings at the time of nephrectomy for renal mass. Ann Surg Oncol. 1997;4(7):570-4.

103. Jinzaki M, Tanimoto A, Narimatsu Y, Ohkuma K, Kurata T, Shimamoto H, et al. Angiomyolipoma: imaging findings in lesions with minimal fat. Radiology. 1997;205(2):497-502.

104. Sherman JL, Hartman DS, Friedman AC, Madewell JE, Davis CJ, Goldman SM. Angiomyolipoma: computed tomographicpathologic correlation of 17 cases. AJR Am J Roentgenol. 1981;137(6):1221-6.

105. Sant GR, Heaney JA, Ucci AA Jr, Sarno RC, Meares EM Jr. Computed tomographic findings in renal angiomyolipoma: a histologic correlation. Urology. 1984;24(3):293-6.

106. Chao DH, Zisman A, Pantuck AJ, Freedland SJ, Said JW, Belldegrun AS. Changing concepts in the management of renal oncocytoma. Urology. 2002;59(5):635-42.

107. Fielding JR, Visweswaran A, Silverman SG, Granter SR, Renshaw AA. CT and ultrasound features of metanephric adenoma in adults with pathologic correlation. J Comput Assist Tomogr. 1999;23(3):441-4.

108. How much does a Kidney Biopsy cost near me? - MDsave [Internet]. Mdsave.com. [cited 2020 Nov 24]. Available from: https://www.mdsave.com/procedures/kidney-biopsy/d78af5c5

109. Sahni VA, Silverman SG. Biopsy of renal masses: when and why. Cancer Imaging. 2009;9(1):44-55.

110. Amin MB, Greene FL, Edge SB, Compton CC, Gershenwald JE, Brookland RK, et al. The Eighth Edition AJCC Cancer Staging Manual: Continuing to build a bridge from a population-based to a more "personalized" approach to cancer staging: The Eighth Edition AJCC Cancer Staging Manual. CA Cancer J Clin. 2017;67(2):93-9.

111. Swami U, Nussenzveig RH, Haaland B, Agarwal N. Revisiting AJCC TNM staging for renal cell carcinoma: the quest for improvement. Ann Transl Med. 2019;7(Suppl 1):S18.

112. Dryden J. Kidney cancer detected early with urine test [Internet]. Wustl.edu. 2015 [cited 2020 Nov 24]. Available from: https://source.wustl.edu/2015/03/kidney-cancer-detected-early-with-urine-test/

113. Morrissey JJ, Kharasch ED. The specificity of urinary aquaporin 1 and perilipin 2 to screen for renal cell carcinoma. J Urol 2013;189(5):1913-20.

114. Kalangutkar PK. Nanotechnology - advancing the field of biomedical engineering. International Journal of Current Research and Review. 2015 May; 7(9):66-70. 